TP Periodica Polytechnica Civil Engineering

61(2), pp. 292-299, 2017

https://doi.org/10.3311/PPci.9339

Creative Commons Attribution (1)

\section{Numerically Based Analysis of Buried GRP Pipelines under Earthquake Wave Propagation and Landslide Effects}

\author{
Mehrzad Tahamouli Roudsari ${ }^{1 *}$, Sina Samet ${ }^{2}$, Nader Nuraie $^{3}$, Shohreh \\ Sohaei $^{4}$
}

RESEARCH ARTICLE $\quad$ Received 15 April 2016; Revised 10 July 2016; Accepted 24 August 2016

\begin{abstract}
Determining the failure criteria and the level of damage in buried pipelines is an important and significant issue and different researchers have studied continuous and segmented steel and concrete pipes. To calculate the failure criterion of Glass Reinforced Polymer (GRP) pipes, first the pipe was tested and the force-displacement diagram of the pipe was drawn up until the failure time. Then, the tested specimen was modelled using finite element software and the lab test results were verified quite accurately. Based on this, by the finite element modeling of GRP pipe with different diameters under bending, the pipe's failure criterion was calculated. Afterwards, straight GRP pipes with different diameters were subjected to landslide and earthquake wave propagation in different clay and sandy soils. The results of finite element analyses in eight different types of soil show the vulnerability of the GRP pipes.
\end{abstract}

\section{Keywords}

Buried GRP Pipelines, Nonlinear Finite Element Analysis, Failure Criterion, Earthquake Wave Propagation, Landslide

${ }^{1}$ Assistant Professor, Department of Civil Engineering, Kermanshah Branch, Islamic Azad University, Kermanshah, Iran

${ }^{2} \mathrm{Ph}$. D. Student, Department of Civil Engineering, Kermanshah Branch, Islamic Azad University, Kermanshah, Iran

${ }^{3}$ M. Sc. in Civil Engineering, Department of Civil Engineering, Kermanshah Branch, Islamic Azad University, Kermanshah, Iran

${ }^{4} \mathrm{Ph}$. D. Student, Department of Civil Engineering, Najaf Abad Branch, Islamic Azad University, Najaf Abad, Iran

"Corresponding author email: tahamouli@iauksh.ac.ir

\section{Introduction}

The importance of lifelines is in the fact that the survival of communities in critical situations and thereafter strictly depends upon them. Thus, damage to these systems after earthquakes offers a lot of trouble in crisis management and rescue operations. The trait which separates a buried pipeline from other structures is that one of its dimensions is very long compared to its other dimensions. This characteristic means that the buried pipeline crosses a vast geographical terrain and can face numerous seismic hazards and different soil specifications.

Investigating the effects of actual earthquakes on buried pipeline networks is mostly performed by calculating the damage functions which provide the number of failures per unit area versus the peak ground velocity or acceleration. These damage functions are empirical and based on the data recorded from previous earthquakes, calculate the extent of damage in the pipeline systems. Eguchi et al [1], for the first time, separated the failure of the pipelines against the permanent ground deformation and earthquake wave propagation. O'Rourke and Ayala [2] acquired the fragility curves against peak ground velocity for different concrete, cast iron and asbestos pipes based on the existing responses from four earthquakes occurred in the United States and two earthquakes in Mexico. Chen et al. [3] carried out studies regarding the damage degree caused by the Chi Chi earthquake on water and gas pipes in Taiwan and presented a set of damage functions.

Shih and Chang [4] evaluated the damages inflicted on water pipelines system caused by Taiwan's Chi Chi earthquake. They reported that earthquake wave propagation and permanent ground deformations contributed to the failures in buried pipelines by 48 and 52 percent, respectively. Damage functions can only present a general estimation of the damage in a network and cannot calculate failure levels, their locations or the network's lack of functionality. Thus, researchers have paid special attention to numerical and analytical methods.

Newmark and Rosenblueth [5] studied the response of buried pipelines subjected to earthquake. They assumed the deformation of the pipe to be similar to that of the ground and also ignored the relative displacement between the pipe and the soil. 
Wang et al [6] improved the previous work. They considered pipelines as semi-rigid components with limited axial stiffness and obtained the pipes' maximum strain.

Other methods were put forward by Shah and Chu [7], Takada [8], Wang et al [9] and O'Rourke et al [10] with each of those employing corrective assumptions regarding the original work done by Newmark and Rosenblueth [5]. O'Rourke and Elhmadi [11] assessed the effects of seismic wave propagation on continuous buried pipelines. By assuming a bilinear behavior for the soil, they obtained the differential equation of the axial vibration of the pipe. They disregarded the axial inertia of the pipe and assumed the wave propagation to be sinusoidal. Ultimately, they calculated the maximum strain of the pipe and showed that the required strain for the slippage between the pipe and the soil is lesser than the failure strain of the pipe. Thus, the occurrence of slippage between the pipe and the soil in the developed axial failures in the pipes is inevitable.

The efforts of Newmark and Hall [12] to model and analyze the behavior of buried pipelines against the movements of faults can be recognized as the first suitable research in that regard. They considered the deformation of the pipe to be axial, defined the movement of the fault in a plane and assumed the soil mass as two moveable rigid bodies on the sides of the fault. Kennedy et al [13] investigated the static response of the buried pipeline subjected to the movement of a strike slip fault. They neglected the bending stiffness of the pipe and considered it as a cable. Wang and Yeh [14] studied the response of the buried pipeline at the location of a strike slip fault having taken into account the bending strength of the pipe. Chio et al [15] meliorated the model recommended by Wang and Yeh [14]. To resolve the shortcoming of the previous model, they considered a variable curvature for the pipe.

It has to be acknowledged that while being efficient, all the aforementioned analytical works are incapable of reflecting a thorough outline of the pipe's response. Therefore, researchers have paid additional attention to numerical models.

Datta and his colleagues [16,17] investigated the dynamic behavior of the buried pipeline in the state of plane strain. They modelled the pipe as an infinite, thin, isotropic, homogeneous, and elastic shell. It was assumed that the soil was a circular trench with the pipe being in its center.

Takada et al [18] noted that the behavior of buried pipelines resembles to that of a shell. According to this and by utilizing the finite element method, they assessed the effect of fault movements on buried pipelines. They proposed a new method to calculate the maximum strain in a pipe by taking into account the deformation of the cross section of the pipe caused by fault movements.

Liu et al [19] presented an equivalent spring to model the boundary conditions of the pipe using the shell model in a fault. The work of Liu et al was to decrease the length of the pipe and replace the removed parts with equivalent springs.
Calvetti and Claudio [20] investigated the interaction between the pipe and soil using a small-scale test and numerical modelling method. Guo and Stolle [21] studied the effect of the experimental model scale on the results of the pipe-soil interaction. Babu and Rao [22] calculated the reliability of the flexible buried pipe under gravity loads.

Rofooei and Qorbani [23] carried out a study on the seismic behavior of buried pipes under wave propagation. In their work, the both ends of the pipe were considered fixed and it was modelled using beam elements and the pipe's interaction with the soil was accounted by using nonlinear springs in three perpendicular directions.

Hosseini and Tahamouli [24] carried out analyzes on buried straight steel pipelines subjected to earthquake wave propagation and presented the concept of minimum effective length based on a numerical model. They showed that the higher modes of the pipe play a significant role in the response of these pipes when subjected to earthquake wave propagation. Tahamouli and Hosseini [25] examined the reliability of buried steel pipeline networks under earthquake wave propagation. It was concluded by them that the reliability of the pipeline network for peak ground displacement of 1.5 meters is above $80 \%$.

Tahamouli et al [26] numerically assessed the interaction between sandy soil and the polyethylene pipe at the location of a strike-slip fault. They showed that the equations given in the ASCE guideline for modelling soil's equivalent springs are, in some cases, exceedingly conservative. Hosseini and Tahamouli [27] presented a new criterion for the occurrence of local buckling in buried steel pipelines. In addition to providing an analytical equation for the minimum effective length of the pipe, they also presented that the buried continuous straight steel pipes will not reach the boundary of local buckling even under strong earthquakes.

Yun and Kang [28] investigated the vulnerability of high pressure buried pipeline under landslide effects. They calculated failure probability and reliability index of the pipeline by using first order second moment reliability method. The results showed the vulnerability of the buried gas pipelines. Luo et al. [29] were analyzed buried polyethylene pipe subjected to seismic landslide by finite element model. The numerical simulation results showed that ovalization of pipe cross sectional area is the main failure mode of buried polyethylene pipe subjected to landslide effect.

As it was seen, extensive amount of research has been done in the field of buried pipelines. In the recent years, the use of GRP pipes has risen drastically, especially in water supplying systems. But no comprehensive research has been performed with regards to the failure criteria and the damage level of these pipes under seismic hazards. In this paper, to calculate the failure criterion of the GRP pipe, a specimen of the pipe was tested in the lab in accordance with the ASTM D2412 guidelines and the force-displacement diagram of the pipe was obtained 
up until the collapse moment. Then, the tested specimen was modelled by the ABAQUS software and the experimental results were verified with considerably high accuracy and also the maximum stress of the pipe at the moment of failure was achieved. On this basis, by the finite element modelling of GRP pipes with different diameters under bending, the failure criterion of the pipe was calculated in terms of the maximum strain. Afterwards, GRP pipes with different diameters were subjected to land slide and earthquake wave propagation in different types of clay and sandy soils. The results of several nonlinear finite element analyzes in eight different soils show the vulnerability of GRP pipes.

\section{Testing the GRP Pipe Based on the ASTM D2412 Guidelines}

The test was performed on a pipe with the diameter, length and thickness equal to 400, 410 and $7.41 \mathrm{~mm}$, respectively. The test was done in the technical lab of Behrad Doroud Lorestan Company which manufactures GRP pipes. As it is illustrated in Fig. 1, the pipe was subjected to a displacement perpendicular to the axis of the pipe with the velocity of 0.0125 meters per second and the force-displacement values were recorded until the collapse of the pipe.

The obtained results from the test are presented in Fig. 2. The behavior of the GRP pipe is brittle and thus it justifies the rather linear diagram in Fig. 2. Due to the unknown location at which the pipe fails, the stress of the failure moment was not recorded in the lab.

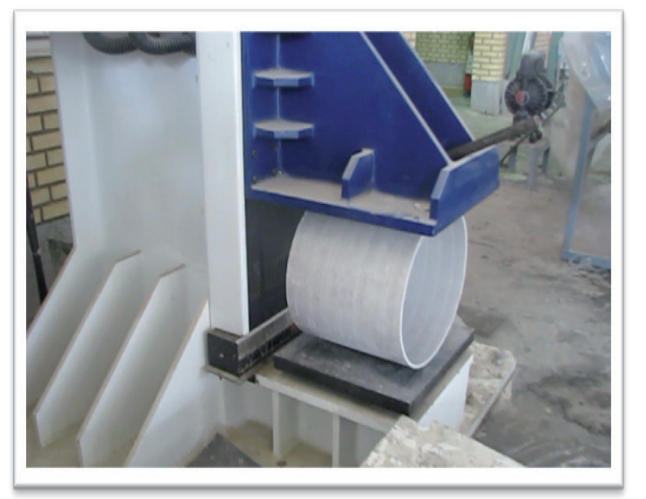

Fig. 1 The GRP pipe under loading in lab of Behrad Doroud Lorestan

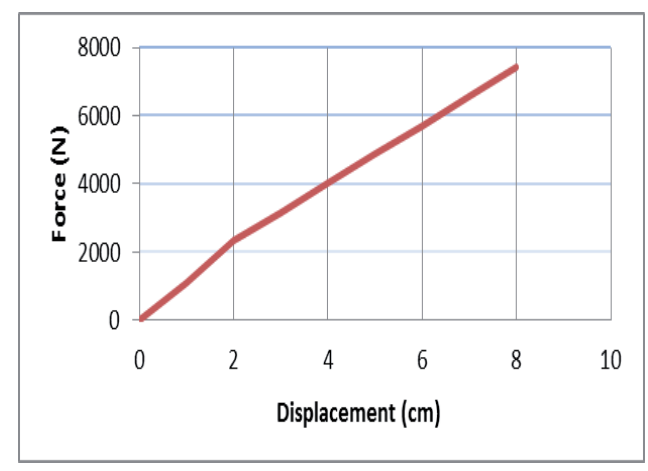

Fig. 2 The pipe's force-displacement diagram obtained from the test

\section{Finite Element Modelling of the Experimental Test}

Table 1 shows the complete specifications of the tested GRP pipe. The pipe was simulated as a 3D model using "shell" elements in a finite element software. The bottom of the pipe was assumed to be fixed and the upper part of the pipe was displaced downward with the same loading velocity in the lab. The behavior of the material was considered linear but geometric nonlinearity was assumed in the analysis. Fig. 3 demonstrates the pipe's final deformed shape in the finite element model.

Table 1 The geometrical and mechanical specifications of the GRP pipe

\begin{tabular}{cc}
\hline Thickness $(\mathbf{m})$ & 0.007405 \\
density $\left(\mathbf{k g} / \mathbf{m}^{3}\right)$ & 2137 \\
Young modulus $(\mathbf{G P a})$ & 12.91 \\
Poissons ratio & 0.3 \\
Length $(\mathbf{m})$ & 0.4145 \\
Internal diameter $(\mathbf{m})$ & 0.40125 \\
Outside diameter $(\mathbf{m})$ & 0.41606 \\
\hline
\end{tabular}
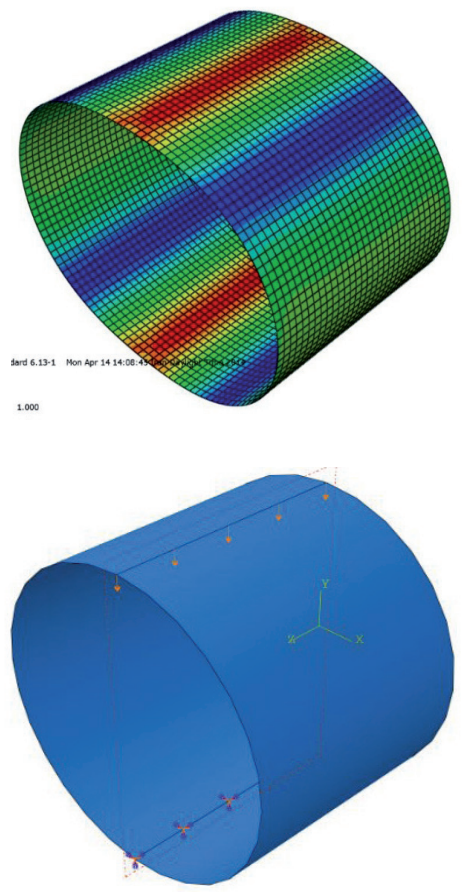

Fig. 3 The boundary conditions and deformed shape of the pipe after loading

Fig. 4 compares the final results of the finite element model with the experimental results. The results have a very good agreement; therefore the maximum tensile stress at the moment of failure can be derived from the finite element model. Based on this, the maximum tensile stress of the pipe was obtained equal to $165 \mathrm{MPa}$. The actual loading condition applied to the buried pipeline by the soil is similar to that carried out in the lab. The majority of the load exerted on the pipe due to settlement or land slide is the bending load which causes curvature and ovalization in the pipe and eventually results in its failure.

It is clear that it's not possible for long pipes to be modelled using shell elements. The model that is shown in Fig. 5 and has 
been employed in this study is a 2D or 3D model in which the pipe and the pipe-soil interaction are modelled using beam elements and equivalent bilinear springs, respectively.

It is evident that the obtained stresses and strains from the model that employs beam elements differs from those obtained from the model which uses shell elements. That's because the pipe's cross section is not properly accounted for in the model that utilizes beam elements. Therefore, the pipe's failure criterion in the next section is calculated based on the strain of the beam element model.

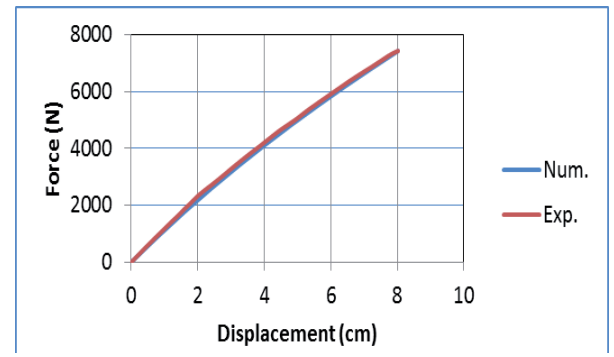

Fig. 4 Comparing finite element and laboratory test results

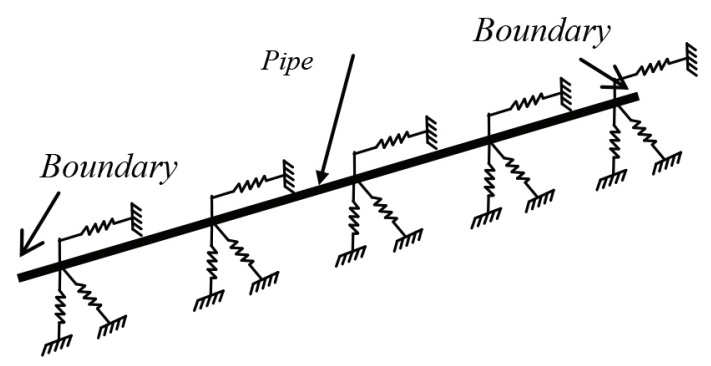

Fig. 5 The common analytical or numerical buried pipe model

\section{Determining the Failure Criterion of the GRP Pipe}

In this section, a pipe with the diameters of 300,400 to 1000 millimetres and the length of $12.5 \mathrm{~m}$ was subjected to pure bending (rotation at both ends). The pipe was modelled using shell elements, the specifications of the GRP pipe were chosen identical to those mentioned in the previous section and also geometrical nonlinearity was assumed in the analysis. At both ends, the circumference of the pipe is constrained to the center of the pipe and the loading was applied in a rotational control manner. The loading was continued until the pipe's maximum tensile stress reached $165 \mathrm{MPa}$. Fig. 6 depicts a sample of the carried out loading.

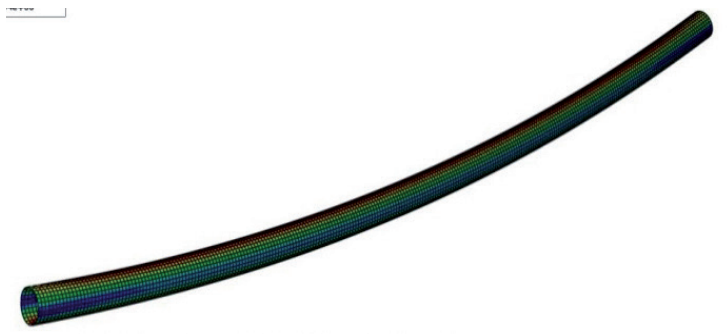

Fig. 6 The 12.5 meter pipe model under pure bending
The moment at which the pipe's stress reached the failure limit was recorded and the same loading was also performed for the pipes modelled with beam elements. The strain in the model with beam elements was recorded right at the moment when the stress in the model with shell elements reached the failure limit. Table 2 demonstrates the acquired results for all the pipes. In this table, $\mathrm{t}$ and $\mathrm{R}$ are the pipe's thickness and radius, respectively, and the third column of the table is the pipe's strain at the moment of failure in the model with beam elements. Thereupon, the failure criterion of the GRP pipe can be expressed as follows:

$$
0.37 \frac{t}{R} \leq \varepsilon \leq 0.44 \frac{t}{R}
$$

Table 2 Failure in pipes with different diameters

\begin{tabular}{ccccc}
\hline $\mathbf{R}(\mathbf{m})$ & $\mathbf{t}(\mathbf{m})$ & $\boldsymbol{\varepsilon}_{\mathbf{r}}$ (Beam Element) & $\mathbf{t} / \mathbf{R}$ & $\boldsymbol{\varepsilon}_{\mathbf{r}} /(\mathbf{t} / \mathbf{R})$ \\
\hline $1.56 \mathrm{E}-01$ & $4.60 \mathrm{E}-03$ & $1.21 \mathrm{E}-02$ & $2.95 \mathrm{E}-02$ & $4.34 \mathrm{E}-01$ \\
$2.07 \mathrm{E}-01$ & $6.00 \mathrm{E}-03$ & $1.18 \mathrm{E}-02$ & $2.90 \mathrm{E}-02$ & $4.06 \mathrm{E}-01$ \\
$2.57 \mathrm{E}-01$ & $7.30 \mathrm{E}-03$ & $1.25 \mathrm{E}-02$ & $2.84 \mathrm{E}-02$ & $4.42 \mathrm{E}-01$ \\
$3.04 \mathrm{E}-01$ & $8.60 \mathrm{E}-03$ & $1.22 \mathrm{E}-02$ & $2.83 \mathrm{E}-02$ & $4.30 \mathrm{E}-01$ \\
$3.55 \mathrm{E}-01$ & $9.80 \mathrm{E}-03$ & $1.13 \mathrm{E}-02$ & $2.76 \mathrm{E}-02$ & $4.11 \mathrm{E}-01$ \\
$4.05 \mathrm{E}-01$ & $1.12 \mathrm{E}-02$ & $1.04 \mathrm{E}-02$ & $2.76 \mathrm{E}-02$ & $3.75 \mathrm{E}-01$ \\
$4.56 \mathrm{E}-01$ & $1.26 \mathrm{E}-02$ & $1.02 \mathrm{E}-02$ & $2.77 \mathrm{E}-02$ & $3.69 \mathrm{E}-01$ \\
$5.06 \mathrm{E}-01$ & $1.38 \mathrm{E}-02$ & $1.01 \mathrm{E}-02$ & $2.73 \mathrm{E}-02$ & $3.71 \mathrm{E}-01$ \\
\hline
\end{tabular}

After calculating the failure criterion of the GRP pipe, the pipe with different diameters and in different soil types was subjected to earthquake wave propagation and land slide and was analyzed in order to evaluate the level of damage laid upon it.

\section{Specifications of the Finite Element Model Employed For Analyzing the Buried Straight GRP Pipe}

For the finite element analysis of the buried GRP pipe, the model shown in Fig. 5 has been used. I.e. the pipe was modelled utilizing beam elements and the length of the pipe was considered in such a way that it satisfied the criteria of the minimum effective length concept [27]. The length of the pipe was assumed long enough so that the support conditions at both ends of the pipe don't affect the results in the pipe's midspan. The mesh size of the model was verified for both wave propagation and land slide cases. The pipe-soil interaction was accounted for based on the bilinear equivalent springs given by ASCE Technical Council on Lifeline Earthquake Engineering (TCLEE) [30]. The actual behavior of the soil and its simplified bilinear behavior is drawn in Fig. 7 . 

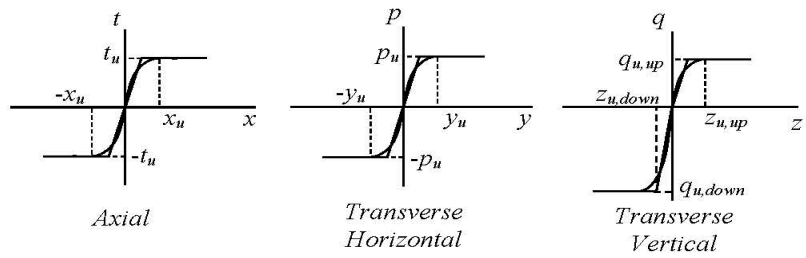

Fig. 7 The actual and simplified behavior of pipe-soil interaction according to ASCE specifications

The behavior of soil's longitudinal and transverse-horizontal springs will be symmetrically considered in both directions. The stiffness of these springs depends on parameters such as the type of the soil, the soil's density, the diameter and the burial depth of the pipe, the internal friction coefficient in the sand and etc. In these diagrams, the parameters $t, p$ and $q$ are the maximum interactional force between the soil and the pipe in the longitudinal, transverse horizontal and vertical directions, respectively. $\mathrm{x}, \mathrm{y}$ and $\mathrm{z}$ are the corresponding displacements at the moment of yield.

Undoubtedly, the soil's characteristics critically affect the response of the pipe. The stiffness of the pipe-soil interaction equivalent springs and even the velocity and the predominant dynamic period of the transitive wave passing through the soil depend on the soil's characteristics. To take into account different types of soils and to investigate their influence on the response of the pipe, four types of soil have been considered for each type of sand and clay [24, 27]. Type I and type IV are respectively the densest and the loosest types of soil. The specifications of all types of soil are presented in Tables 3 and 4.

Table 3 The employed specifications for different types of sand [24, 27]

\begin{tabular}{llllllll}
\hline Sand type & $\phi$ & $\boldsymbol{\gamma}$ & $\mathbf{k}$ & $\mathbf{k}_{\mathbf{0}}$ & $\mathbf{T}$ & $\mathbf{V}_{\mathbf{s}}$ & $\boldsymbol{\lambda}$ \\
\hline I & 35 & 21000 & 0.7 & 1.5 & 0.4 & 625 & 250 \\
II & 33 & 20000 & 0.65 & 1.2 & 0.5 & 500 & 250 \\
III & 31 & 19000 & 0.55 & 0.8 & 0.7 & 275 & 192.5 \\
IV & 30 & 18000 & 0.5 & 0.5 & 1 & 150 & 150 \\
\hline
\end{tabular}

Table 4 The employed specifications for different types of clay [24, 27]

\begin{tabular}{llllll}
\hline Clay type & $\boldsymbol{\gamma}$ & Su & T & vs & $\boldsymbol{\lambda}$ \\
\hline I & 21000 & 160000 & 0.4 & 625 & 250 \\
II & 20500 & 100000 & 0.5 & 500 & 250 \\
III & 19500 & 60000 & 0.7 & 275 & 192.5 \\
IV & 19000 & 40000 & 1 & 150 & 150 \\
\hline
\end{tabular}

In these tables $\phi, \gamma, \mathrm{k}, \mathrm{k}_{0}, \mathrm{~S}_{\mathrm{u}}, \mathrm{T}, \mathrm{V}_{\mathrm{s}}$, and $\lambda$ are the internal friction coefficient of sand in terms of degrees, the soil's density in terms of $\mathrm{N} / \mathrm{m}^{3}$, friction reduction coefficient of the pipe and the soil, lateral soil pressure at rest, the undrained shear strength of the unconfined soil in terms of $\mathrm{N} / \mathrm{m}^{2}$, the soil's dynamic period in terms of seconds, shear wave velocity in the soil in terms of $\mathrm{m} / \mathrm{s}$ and the wave length in terms of meters, respectively.

\section{Investigating the Damage Imposed Upon the Buried GRP Pipe under Earthquake Wave Propagation}

The earthquake's wave propagation in soil is so that the displacement records, apart from having phase difference, differ from one another in frequency content as well. In this research, the difference in the frequency content has been neglected and only the records' time delay caused by the velocity of the wave has been taken into consideration. Therefore, the bases of the soil's equivalent springs were excited with a wave velocity dependent time delay.

The GRP pipe with three different diameters of 300, 600 and 1000 millimetres was subjected to the "Kobe" and "Chi Chi" earthquakes' displacement records in two types of dense and loose (Types I and IV) for both clay and sandy soils. A total of 24 time history nonlinear dynamic analyzes with the large deformation assumption were carried out. Fig. 8 depicts the displacement record of the considered earthquakes with respect to time.
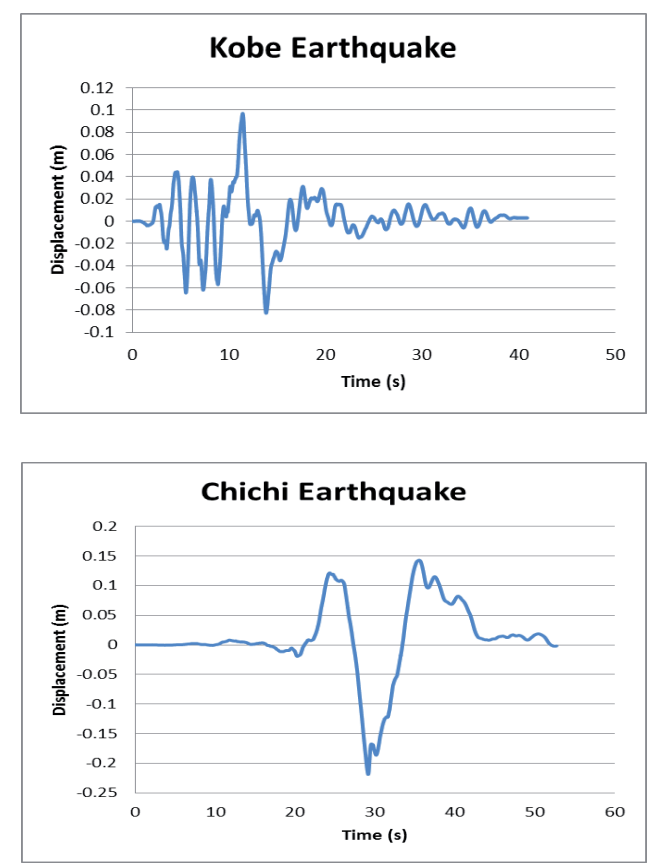

Fig. 8 The displacement records of Kobe and Chi Chi earthquakes

In this case, the finite element model was assumed two dimensional and the earthquake record was transverse-horizontally applied to the pipe and also the strain of the midpoint of the pipe was calculated with respect to time. Fig. 9, as an example, shows the response of the GRP pipe with the diameter of 300 millimetres to the Kobe earthquake in sand type IV. The maximum strain of the midpoint of the pipe was 0.02209 and according to Table 2, it causes the pipe to fail.

The results of 24 time-history nonlinear dynamic analyzes are given in Table 5. The last column of the table signifies the occurrence or nonoccurrence of failure in the pipe. It can be said that failure in the buried straight GRP pipe with different diameters is quite probable when being under the influence of 
an average or strong earthquake's wave propagation, whereas in the buried continuous steel pipe, wave propagation almost doesn't possess the capability to cause local buckling and bring about any kind of danger [27].

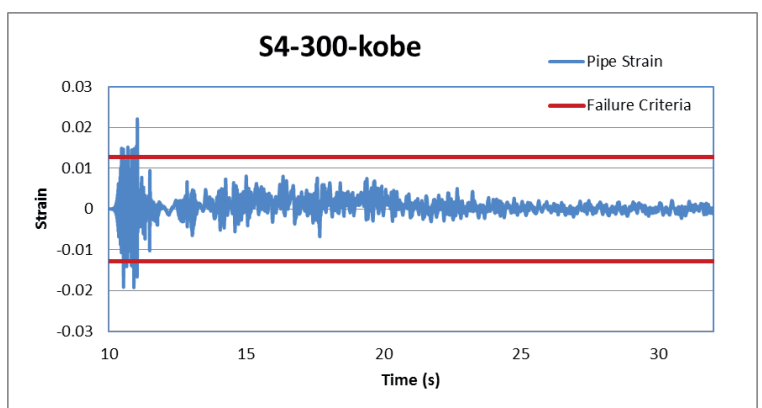

Fig. 9 Time-history of the strain at the mid-point of the pipe with the diameter of $300 \mathrm{mms}$ in sand type IV under the Kobe earthquake record

Table 5 The results from 24 time-history nonlinear dynamic analyzes

\begin{tabular}{|c|c|c|c|c|c|}
\hline $\begin{array}{c}\text { Pipe } \\
\text { Diameter } \\
(\mathrm{mm})\end{array}$ & $\begin{array}{l}\text { Failure } \\
\text { Strain }\end{array}$ & $\begin{array}{l}\text { Soil } \\
\text { Type }\end{array}$ & $\begin{array}{c}\text { Earthquake } \\
\text { Record }\end{array}$ & $\begin{array}{c}\text { Max } \\
\text { Strain }\end{array}$ & Damage \\
\hline \multirow{8}{*}{300} & \multirow{8}{*}{0.012786} & \multirow{2}{*}{$\mathrm{S} 1$} & ChiChi & 0.011777 & No \\
\hline & & & Kobe & 0.015869 & Yes \\
\hline & & \multirow{2}{*}{ S4 } & ChiChi & 0.029078 & Yes \\
\hline & & & Kobe & 0.022091 & Yes \\
\hline & & \multirow{2}{*}{$\mathrm{C} 1$} & ChiChi & 0.009214 & No \\
\hline & & & Kobe & 0.014017 & Yes \\
\hline & & \multirow{2}{*}{$\mathrm{C} 4$} & ChiChi & 0.017598 & Yes \\
\hline & & & Kobe & 0.020055 & Yes \\
\hline \multirow{8}{*}{600} & \multirow{8}{*}{0.012163} & \multirow{2}{*}{ S1 } & ChiChi & 0.010778 & No \\
\hline & & & Kobe & 0.020344 & Yes \\
\hline & & \multirow{2}{*}{ S4 } & ChiChi & 0.037308 & Yes \\
\hline & & & Kobe & 0.021439 & Yes \\
\hline & & \multirow{2}{*}{$\mathrm{C} 1$} & ChiChi & 0.015384 & Yes \\
\hline & & & Kobe & 0.014006 & Yes \\
\hline & & \multirow{2}{*}{$\mathrm{C} 4$} & ChiChi & 0.022366 & Yes \\
\hline & & & Kobe & 0.041502 & Yes \\
\hline \multirow{8}{*}{1000} & \multirow{8}{*}{0.0101095} & \multirow{2}{*}{ S1 } & ChiChi & 0.017689 & Yes \\
\hline & & & Kobe & 0.015477 & Yes \\
\hline & & \multirow{2}{*}{ S4 } & ChiChi & 0.028248 & Yes \\
\hline & & & Kobe & 0.025914 & Yes \\
\hline & & \multirow{2}{*}{$\mathrm{C} 1$} & ChiChi & 0.016365 & Yes \\
\hline & & & Kobe & 0.011181 & Yes \\
\hline & & \multirow{2}{*}{$\mathrm{C} 4$} & ChiChi & 0.028102 & Yes \\
\hline & & & Kobe & 0.025405 & Yes \\
\hline
\end{tabular}

By carefully observing Table 5 it can be concluded that:

By increasing the density of the soil, the maximum strain developed in the pipe decreases. In the pipe with the diameter of 300 millimetres, the maximum strain was produced in the loose sandy soil. In the pipe with the diameter of 600 millimetres, the maximum strain was produced in the soft clay soil. In the pipe with the diameter of 1000 millimetres, the maximum strains were almost the same in both soft clay and loose sand.
By increasing the diameter of the pipe from 300 to 600 millimetres, the maximum strain increases also. But this increase is not seen when the diameter of the pipe changes from 600 to $1000 \mathrm{~mm}$.

\section{Assessing the Damage Inflicted on the Buried GRP Pipe Subjected to Landslide Effect}

To investigate the effect of landslide on the buried GRP pipe, the ground's movement pattern was considered as [31]:

$$
y(x)=\frac{\delta}{2}\left(1-\cos \frac{2 \pi x}{W}\right)
$$

In which $\delta$ and $\mathrm{W}$ are the maximum displacement and the width of the landslide, respectively. Fig. 10 illustrates an example of the landslide pattern. Pipes with different diameters and in different types of sandy and clay soils were subjected to landslide with a cosinusoidal pattern. The displacements were applied to the base of the soil's equivalent springs at the midspan of the pipeline according to Eq. (2).

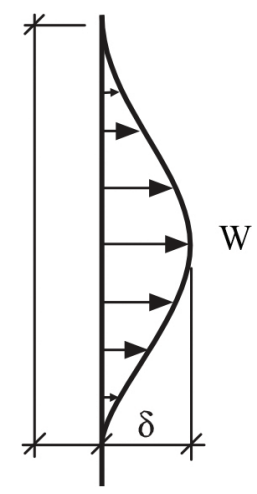

Fig. 10 The cosinusoidal pattern for the landslide

Previous studies reveal that the maximum strain developed in the pipe is due to the landslide with the length of about 30 meters and also the maximum strains in pipes are constant for landslides with the lateral displacement of more than 1.5 meters [31]. Thus, in the analyzes performed in this section, the length $(\mathrm{W})$ and the maximum lateral displacement $(\delta)$ of the landslide were considered equal to 30 and 3 meters, respectively. 64 nonlinear analyzes were carried out and the maximum strain of the pipe for each case was obtained. Results show that failure has occurred in all pipes with different diameters in each of 8 types of soil. For every pipe, the least required value of $\delta$ corresponding to the failure moment was calculated. The results for the sandy soil are presented in Tables 6 and 7 and the results for clay soil are given in Tables 8 and 9 . 
Table 6 The maximum axial strain of the GRP pipe in sandy soil under the landslide with the maximum displacement of 3 meters

\begin{tabular}{cccccc}
\hline $\mathbf{R}(\mathbf{m})$ & $\mathbf{t}(\mathbf{m})$ & $\mathbf{S 4}$ & $\mathbf{S 3}$ & $\mathbf{S 2}$ & $\mathbf{S 1}$ \\
\hline $1.56 \mathrm{E}-01$ & 0.0046 & 0.016 & 0.017 & 0.019 & 0.021 \\
$2.07 \mathrm{E}-01$ & 0.006 & 0.019 & 0.019 & 0.021 & 0.023 \\
$2.57 \mathrm{E}-01$ & 0.0073 & 0.021 & 0.022 & 0.022 & 0.024 \\
$3.04 \mathrm{E}-01$ & 0.0086 & 0.021 & 0.021 & 0.022 & 0.022 \\
$3.55 \mathrm{E}-01$ & 0.0098 & 0.023 & 0.023 & 0.022 & 0.021 \\
$4.05 \mathrm{E}-01$ & 0.0112 & 0.022 & 0.021 & 0.020 & 0.019 \\
$4.56 \mathrm{E}-01$ & 0.0126 & 0.020 & 0.019 & 0.018 & 0.018 \\
$5.06 \mathrm{E}-01$ & 0.0138 & 0.019 & 0.019 & 0.019 & 0.018
\end{tabular}

Table 7 The minimum $\delta$ corresponding to the failure moment of the GRP pipe in sandy soil

\begin{tabular}{cccccc}
\hline $\mathbf{R}(\mathbf{m})$ & $\mathbf{t}(\mathbf{m})$ & $\mathbf{S 4}$ & $\mathbf{S 3}$ & $\mathbf{S 2}$ & $\mathbf{S 1}$ \\
\hline $1.56 \mathrm{E}-01$ & 0.0046 & 2.268 & 2.166 & 1.986 & 1.890 \\
$2.07 \mathrm{E}-01$ & 0.006 & 1.824 & 1.776 & 1.665 & 1.599 \\
$2.57 \mathrm{E}-01$ & 0.0073 & 1.704 & 1.683 & 1.587 & 1.524 \\
$3.04 \mathrm{E}-01$ & 0.0086 & 1.500 & 1.503 & 1.425 & 1.374 \\
$3.55 \mathrm{E}-01$ & 0.0098 & 1.257 & 1.269 & 1.215 & 1.179 \\
$4.05 \mathrm{E}-01$ & 0.0112 & 1.044 & 1.077 & 1.035 & 1.002 \\
$4.56 \mathrm{E}-01$ & 0.0126 & 1.011 & 0.999 & 0.951 & 0.915 \\
$5.06 \mathrm{E}-01$ & 0.0138 & 0.864 & 0.936 & 0.936 & 0.843 \\
\hline
\end{tabular}

Table 8 The maximum axial strain of the GRP pipe in clay soil under the landslide with the maximum displacement of 3 meters

\begin{tabular}{cccccc}
\hline $\mathbf{R}(\mathbf{m})$ & $\mathbf{t}(\mathbf{m})$ & $\mathbf{C 4}$ & $\mathbf{C 3}$ & $\mathbf{C 2}$ & $\mathbf{C 1}$ \\
\hline $1.56 \mathrm{E}-01$ & 0.0046 & 0.020 & 0.025 & 0.026 & 0.027 \\
$2.07 \mathrm{E}-01$ & 0.006 & 0.018 & 0.024 & 0.028 & 0.029 \\
$2.57 \mathrm{E}-01$ & 0.0073 & 0.016 & 0.023 & 0.030 & 0.031 \\
$3.04 \mathrm{E}-01$ & 0.0086 & 0.014 & 0.020 & 0.030 & 0.032 \\
$3.55 \mathrm{E}-01$ & 0.0098 & 0.016 & 0.023 & 0.033 & 0.035 \\
$4.05 \mathrm{E}-01$ & 0.0112 & 0.015 & 0.021 & 0.032 & 0.037 \\
$4.56 \mathrm{E}-01$ & 0.0126 & 0.013 & 0.019 & 0.029 & 0.039 \\
$5.06 \mathrm{E}-01$ & 0.0138 & 0.012 & 0.019 & 0.029 & 0.041 \\
\hline
\end{tabular}

Table 9 The minimum $\delta$ corresponding to the failure moment of the GRP pipe in clay soil

\begin{tabular}{cccccc}
\hline $\mathbf{R}(\mathbf{m})$ & $\mathbf{t}(\mathbf{m})$ & $\mathbf{C 4}$ & $\mathbf{C 3}$ & $\mathbf{C 2}$ & $\mathbf{C 1}$ \\
\hline $1.56 \mathrm{E}-01$ & 0.0046 & 1.764 & 1.740 & 1.716 & 1.710 \\
$2.07 \mathrm{E}-01$ & 0.006 & 1.524 & 1.506 & 1.488 & 1.482 \\
$2.57 \mathrm{E}-01$ & 0.0073 & 1.467 & 1.446 & 1.431 & 1.422 \\
$3.04 \mathrm{E}-01$ & 0.0086 & 1.338 & 1.320 & 1.305 & 1.296 \\
$3.55 \mathrm{E}-01$ & 0.0098 & 1.161 & 1.149 & 1.137 & 1.131 \\
$4.05 \mathrm{E}-01$ & 0.0112 & 0.999 & 0.987 & 0.975 & 0.969 \\
$4.56 \mathrm{E}-01$ & 0.0126 & 0.924 & 0.909 & 0.897 & 0.888 \\
$5.06 \mathrm{E}-01$ & 0.0138 & 0.879 & 0.843 & 0.828 & 0.822 \\
\hline
\end{tabular}

From investigating Tables 6 and 7 it can be concluded that:

- With the diameter of the pipe increasing in different types of sand, first the pipe's maximum strain increases but for the very large pipes the strain decreases again.
- For smaller pipes by increasing the sand's density, the strain developed in the pipe increases but for larger pipes the strain decreases.

- By increasing the diameter of the pipe, a smaller $\delta$ is needed for the pipe to arrive at the failure limit.

- By increasing the density of sand, a smaller $\delta$ is required for the pipe to reach the failure limit.

- The displacement required for the GRP pipe to fail when subjected to landslide in sandy soil is between 0.8 and 2.3 meters.

From investigating Tables 8 and 9 it can be concluded that:

- With the diameter of the pipe increasing in stiff clay, the pipe's maximum strain increases but for soft clay vice versa holds.

- With the density of clay increasing, the maximum strain of the pipe increases.

- By increasing the diameter of the pipe, a smaller $\delta$ is needed for the pipe to arrive at the failure limit.

- By increasing the density of clay, a smaller $\delta$ is required for the pipe to reach the failure limit.

- The displacement required for the GRP pipe to fail when subjected to landslide in clay soil is between 0.8 and 1.8 meters.

Compared to clay soil, a higher displacement is needed for the GRP pipe buried in sandy soil to arrive at the failure limit.

\section{Conclusions}

In this paper, to calculate the failure criterion of the GRP pipe, a specimen of the pipe was subjected to loading in the lab in accordance with the ASTM-D2412 guideline and the pipe's Force-Displacement diagram was obtained up to the failure moment. Then, by modelling the GRP pipe with different diameters in a finite element software, the failure criterion was calculated based on the maximum strain. Thereafter, the GRP pipe with different diameters was subjected to landslide and earthquake wave propagation in different types of sandy and clay soils. The results show that it's very probable for the buried straight GRP pipe with different diameters to fail when subjected to an average or strong earthquake's wave propagation. With the density of the soil increasing, the pipe's maximum strain developed due to wave propagation attenuates. The displacement with which the GRP pipes fail when subjected to landslide is between 0.8 to 2.3 meters in sandy soil and between 0.8 to 1.8 meters in clay soil. By increasing the diameter of the pipe and the density of the soil, the GRP pipe reaches the failure limit faster when it's subjected to landslide.

\section{Acknowledgment}

The authors would like to specially thank the technical lab of Behrad Doroud Lorestan Company and the research lab of the Islamic Azad University of Kermanshah. 


\section{References}

[1] Eguchi, R., Taylor, C., Hasselman, T. "Seismic component vulnerability models for lifeline risk analysis." Technical Report, No. 82-1396-2C, J. H. Wiggins Co., Redondo Beach, CA. 1983.

[2] O'Rourke, M., Ayala, G. "Pipeline damage due to wave propagation." Journal of Geotechnical Engineering. 119 (9), pp. 1490-1498. 1993. DOI: 10.1061/(ASCE)0733-9410(1993)119:9(1490)

[3] Chen, W. W., Shih, B. J., Chen, Y. C., Hung, J. H., Hwang, H. H. “Seismic response of natural gas and water pipelines in the Ji-Ji earthquake." Soil Dynamics and Earthquake Engineering. 22 (9-12), pp. 1209-1214. 2002. DOI: 10.1016/S0267-7261(02)00149-5

[4] Shih, B. J., Chang, C. H. "Damage Survey of Water Supply Systems and Fragility Curve of PVC Water Pipelines in the Chi-Chi Taiwan Earthquake.” Natural Hazards. 37 (1-2), pp. 71-85. 2006. DOI: 10.1007/ s11069-005-4657-9

[5] Newmark, N. M., Rosenblueth, E. "Fundamentals of Earthquake Engineering.”640 p. Prentice-Hall, Engelewood Cliffs, New Jersey. 1971. http://www.worldcat.org/title/fundamentals-of-earthquake-engineering/ oclc/210504

[6] Wang, L. R. L., O’Rourke, M. J., Pikul, R. R. "Seismic vulnerability behavior and design of buried pipelines." Tech. Report No. 9, Dept. of Civil Engineering R.P.I. Troy, N.Y. 1979.

[7] Shah, H. H., Chu, S. L. "Seismic analysis of underground structural elements." Journal of the Power Division. 100 (1), pp. 53-62. 1974. http://cedb.asce.org/CEDBsearch/record.jsp?dockey=0021627

[8] Takada, S. "Earthquake resistant design of underground pipelines." In: 6th World Conference on Earthquake Engineering, New Delhi, pp. 33763381. 1977.

[9] Wang, L. R., Pikul, R. R., O’Rourke, M. J. "Imposed ground strain and buried pipelines." Journal of the Technical Councils of ASCE. 108 (2), pp. 259-263. 1982. http://cedb.asce.org/CEDBsearch/record. jsp?dockey $=0034755$

[10] O’Rourke, M. J., Pikul, R. R., Wang, L. R. "Transverse seismic waves at pipeline junctions." Journal of the Technical Councils of ASCE. 108 (1), pp. 173-177. 1982. http://cedb.asce.org/CEDBsearch/record. jsp?dockey $=0034242$

[11] O’Rourke, M. J., Hmadi, K. E. “Analysis of continuous buried pipelines for seismic wave effects." Earthquake engineering \& structural dynamics. 16 (6), pp. 917-929. 1988. DOI: 10.1002/eqe.4290160611

[12] Newmark, N. M., Hall, W. I. "Pipeline design to resist large fault displacement." In: Proceeding of the U.S. National Conference on Earthquake Engineering, Okland, USA. 1975.

[13] Kennedy, R. P., Williamson, R. A., Chow, A. W. "Fault movement effect on buried oil pipeline." Transportation Engineering Journal of ASCE. 103 (5), pp. 617-633. 1977. http://cedb.asce.org/CEDBsearch/record. jsp?dockey $=0007585$

[14] Wang, L. R. L., Yeh, Y. “A refined seismic analysis and design of buried pipeline for fault movement." Earthquake engineering \& structural dynamics. 13 (1), pp. 75-96. 1985. DOI: 10.1002/eqe.4290130109

[15] Chiou, Y. J., Chi, S. Y., Chang, H. Y. “A study on buried response to fault movement." Journal of Pressure Vessel Technology. 116 (1), pp. 36-41. 1994. DOI: $10.1115 / 1.2929556$

[16] Datta, S. K., Shah, A. H., El-Akily, N. "Dynamic behavior of a buried pipe in a seismic environment." Journal of Applied Mechanics. 49 (1), pp. 141-148. 1982. DOI: 10.1115/1.3161957

[17] Datta, S. K., Shah,A.H., Wong, K.C. "Dynamic stresses and displacements in buried pipe." Journal of engineering mechanics. 110 (10), pp. 14511466. 1984. DOI: 10.1061/(ASCE)0733-9399(1984)110:10(1451)
[18] Takada, S., Hassani, N., Fukuda, K. “A new proposal for simplified design of buried steel pipes crossing active faults." Earthquake Engineering and Structural Dynamics. 30 (8), pp. 1243-1257. 2001. DOI: 10.1002/eqe.62

[19] Liu, A. W., Hu, Y. X., Zhao, F. X., Li, X. J., Takada, S., Zhao, L. “An equivalent boundary method for the shell analysis of buried pipelines under fault movement." ACTA Seismologica Sinica. 17 (Suppl. 1), pp. 150-156. 2004. DOI: 10.1007/s11589-004-0078-1

[20] Calvetti, F., Prisco, C., Nova, R. "Experimental and numerical analysis of soil-pipe interaction." Journal of Geotechnical and Geoenvironmental Engineering. 130 (12), pp. 1292-1299. 2004. DOI: 10.1061/(ASCE)10900241(2004)130:12(1292)

[21] Guo, P. J., Stolle, D. F. E. "Lateral pipe soil interaction in sand with reference to scale effect." Journal of Geotechnical and Geoenvironmental Engineering. 131 (3), pp. 338-349. 2005. DOI: 10.1061/(ASCE)10900241(2005)131:3(338)

[22] Babu, G. L. S., Rao, R. S. "Reliability measures for buried pipes." Canadian Geotechnical Journal. 42 (2), pp. 541-549. 2005. DOI: 10.1139/t04-116

[23] Rofooie, F. R., Qorbani, R. "A parametric study on seismic behavior of continuous buried pipelines due to wave propagation.” In: Proceedings of the 14th World Conference on Earthquake Engineering, Beijing, China. 2008.

[24] Hosseini, M., Roudsari, M. T. "A study on the effect of surface transverse waves on buried steel pipelines considering the nonlinear behavior of soil and pipes." In: Proceedings of the ASCE Pipeline 2010 Conference, Kingston, Colorado, USA. pp. 1078-1087. 2010. DOI: 10.1061/41138(386)103

[25] Roudsari, M. T., Hosseini, M. "Using Neural Network for Reliability Assessment of Buried Steel Pipeline Networks Subjected to Earthquake Wave Propagation." Journal of Applied Sciences. 11 (18), pp. 3233-3246. 2011. DOI: $10.3923 /$ jas.2011.3233.3246

[26] Roudsari, M. T., Seif, M. A., Jamshidi, K. H. "Numerical Study of PipeSoil Interaction Subjected to Strike-Slip Faulting." In: International Conference on Pipelines and Trenchless Technology, Xi'an, China. pp. 695-704. 2013. DOI: 10.1061/9780784413142.072

[27] Hosseini, M., Roudsari, M. "Minimum Effective Length and Modified Criteria for Damage Evaluation of Continuous Buried Straight Steel Pipelines Subjected to Seismic Waves.” Journal of Pipeline Systems Engineering and Practice. 6 (4), 04014018. 2015. DOI:10.1061/(ASCE) PS.1949-1204.0000193

[28] Yun, L., Kang, L. "Reliability Analysis of High Pressure Buried Pipeline under Landslide." Applied Mechanics and Materials. 501-504, pp. 10811086. 2014. DOI: 10.4028/www.scientific.net/AMM.501-504.1081

[29] Luo, X., Ma, J., Zheng, J., Shi, J. "Finite Element Analysis of Buried Polyethylene Pipe Subjected to Seismic Landslide." Journal of Pressure Vessel Technology. 136 (3), 031801. 2014. DOI: 10.1115/1.4026148

[30] ASCE, American Society of Civil Engineers. "Guidelines for the seismic design of oil and gas pipeline systems." Committee on Gas and Liquid Fuel Lifelines of the ASCE Technical Council on Lifeline Earthquake Engineering, Ch. 7, New York. 1984. http://cedb.asce.org/CEDBsearch/ record.jsp?dockey $=0042895$

[31] O'Rourke, T. D. “Critical aspects of soil-pipeline interaction for large ground deformation.” In: Proceedings of the First Japan-US Workshop on Liquefaction, Large Ground Deformation and Their Effects Lifeline Facilities. Tokyo, Japan. pp. 118-126. 1988. 